Talía. Revista de estudios teatrales

ISSN-e 2659-806X

\title{
Mapa de compañías y festivales del teatro para la primerísima infancia en España $^{1}$
}

\author{
Eva Llergo Ojalvo*; Ignacio Ceballos Viro**
}

Recibido: 28 de enero de 2020 / Aceptado: 30 de junio de 2020

Resumen. El teatro para la primerísima infancia, dirigido a espectadores menores de 3 años, es un fenómeno en auge en la escena contemporánea. El número de compañías, espectáculos, festivales y ciclos que se dirigen a esta franja de edad ha ido creciendo desde su aparición en España a principios del siglo XXI. Ante esta nueva manifestación, en este artículo realizamos un inventario de compañías, clasificamos sus obras, registramos su aparición cronológica y ofrecemos un mapa con la ubicación geográfica de cada una. El análisis de todos estos datos relativos al ecosistema del teatro para los más pequeños nos permite ofrecer una caracterización global del fenómeno en España.

Palabras clave: Teatro infantil; Artes escénicas; Primera infancia; Bebés.

\section{[en] A map of theatre companies and festivals for the early years in Spain}

\begin{abstract}
Theatre for the Early Years, aimed at audiences under 3 years old, is a flourishing phenomenon in the contemporary scene. The number of companies, shows, festivals and programming that address this age group has been growing since its appearance in Spain at the beginning of the 21st century. Given this new fact, in this article we carry out an inventory of companies, classify their works, record their chronological appearance and offer a map with the geographical location of each one. The analysis of all these data related to the theatre ecosystem for the very young allows us to offer a global characterization of the phenomenon in Spain.
\end{abstract}

Keywords: Children's theatre, Performing arts, Early childhood, Babies.

Cómo citar: Llergo Ojalvo, E.; Ceballos Viro, I. (2020). Mapa de compañías y festivales del teatro para la primerísima infancia en España, en Talía. Revista de estudios teatrales, 2, 17-27.

\section{La investigación sobre el teatro para la primerísima infancia}

El teatro para la infancia experimenta actualmente un proceso de ampliación de las edades a las que va dirigido. Esta ampliación se produce tanto hacia arriba, con la creación y puesta en escena de obras específicamente para adolescentes, como hacia abajo, con la inclusión de la franja de edad 0-3 años como destinatarios. Se trata, en este último caso, del llamado teatro para la primerísima infancia, o teatro para bebés ${ }^{2}$.
¿Cómo es posible un teatro dirigido a niños de tan corta edad? En estudios teóricos recientes [Schneider 2009, de modo global; Llergo Ojalvo y Ceballos Viro 2019 en el terreno español] se constata una preocupación de las compañías dedicadas a este tipo de teatro por la adecuación al desarrollo cognitivo infantil, por la educación estética desde modelos multisensoriales, por la reproducción de patrones vinculados al juego infantil (y por ello reconocibles para los bebés), como elementos, entre otros, que posibilitan esta creación artística para esas edades.

\footnotetext{
Este estudio ha sido elaborado en el marco del Proyecto de Investigación REC-LIT. Reciclajes culturales: transliteraturas en la era postdigital (Referencia RTI2018-094607-B-I00), financiado por el Ministerio de Ciencia, Innovación y Universidades.

* Universidad Nebrija Email: ellergo@nebrija.es

** Universidad Camilo José Cela Email: iceballos@ucjc.edu

2 Las denominaciones en otros idiomas no son del todo idénticas: Theatre for the Early Years / for the Very Young, théâtre pour la petite enfance / les tous petits, teatro per la primissima infanzia, etc. 
La investigación en torno al teatro para la primerísima infancia se encuentra aún en un estadio, digámoslo así, también primerísimo. Existen investigaciones y reflexiones fundacionales, por ejemplo, en el ámbito anglosajón [Fletcher-Watson, Fletcher-Watson, McNaughton y Birch 2014], en el francés [Ben Soussan y Mignon, 2006], en el italiano [Frabetti, Manferrari, Marchesi y Vassuri 2000], en el escandinavo [Hovik 2014 y 2018], etc. La corta historia de este teatro ya ha hecho, sin embargo, esfuerzos por aunar la práctica escénica con la investigación académica; por ejemplo, con la celebración en 2009 en Bolonia del Forum Internacional "Theatre for the Very Young", como parte del festival internacional "Visioni di Futuro, Visioni di Teatro", o también con la conformación en 2005 de la Red Europea Small Size, o con el empuje investigador dentro de la International Theatre for Young Audiences Research Network (ITYARN). Pero en España no hay demasiado trabajo investigador al respecto [estudios parciales de obras, como Álvarez Uria et al. 2015, y Camino Ortiz et al. 2015, y el estudio global de Llergo Ojalvo y Ceballos Viro 2019].

Aunque si el punto de vista teorizador es, pese a necesario, escaso, la experiencia práctica escénica es cada vez mayor en nuestro país. Asimismo, y como enseguida expondremos, parece contundente el creciente éxito social de esta nueva forma teatral, evidenciando la acogida favorabilísima por parte de familias y escuelas como principales mediadores literarios.

\section{Hacia un mapa del teatro para la primerísima infancia en España}

La investigación acerca del teatro para la primerísima infancia puede tomar, a nuestro juicio, multitud de rumbos muy interesantes, desde la creación escénica, hasta la psicología del desarrollo y de la atención; en este último sentido, es indispensable la consulta de la investigación de Ribagorda [2018], quien junto con Carlos Laredo está realizando aplicaciones a la recepción desde la neurociencia. Pero previamente parece obligado definir este teatro ya existente, caracterizarlo y establecer un panorama general de su presencia en el sistema escénico y literario español.

Este es el objetivo de la presente investigación: desarrollar un mapa del teatro para la primerísima infancia en España. Entendemos por ello toda obra escénica destinada explícita y prioritariamente a la franja de edad 0-3 años. Como se verá más adelante, recogemos en nuestra definición una amplia variedad de prácticas teatrales, en un sentido lato del término.

El propósito es ofrecer una herramienta visual y práctica que permita el acceso a la información sobre las compañías y a las obras, así como posteriores análisis de tipo cuantitativo y cualitativo. Esta herramienta puede ser útil para investigadores, artistas, público y crítica, y, para ello, se ha desarrollado en la aplicación Click2map, y se ha colgado en abierto en la web ${ }^{3}$.

\section{Nuestro proceso de trabajo}

El proceso para la configuración de ese mapa se desarroló en las siguientes fases:

1. Localización, inventario y análisis de los festivales de teatro y artes escénicas para la primerísima infancia. Esta fase se desarrolló mediante un periodo previo de entrevistas a compañías y creadores [Llergo Ojalvo y Ceballos Viro 2019], y un posterior rastreo sistemático por internet: buscadores generales, prensa cultural y prensa local, webs de teatros, webs de compañías especializadas, y grupos temáticos en las principales redes sociales.

2. Vaciado de información de las programaciones de los festivales y ciclos encontrados, para la elaboración de un listado de compañías teatrales dedicadas total o parcialmente a espectáculos para la primerísima infancia.

3. Análisis y clasificación de los espectáculos, con el fin de establecer una clasificación genérica orientativa que permita discernir los planteamientos escénicos de las compañías.

4. Ubicación geográfica en el mapa virtual en línea y elaboración de las fichas descriptivas de cada compañía, de acuerdo con la clasificación establecida en el análisis previo.

5. Encuesta y primera difusión: una vez configurada una primera versión del mapa, se contactó por correo electrónico con todas las compañías inventariadas para solicitarles la comprobación de sus datos y la incorporación de sugerencias. Asimismo, la presentación del mapa ante investigadores de la Asociación ANILIJ en septiembre de 2019 permitió la recogida de añadidos. Un 40\% de las compañías contactadas respondió añadiendo la información solicitada; algunas de ellas también nos pusieron en contacto con otras compañías que aún no habían sido identificadas en nuestras búsquedas ${ }^{4}$.

6. Adición al mapa de las informaciones recogidas en la fase de encuesta.

7. Difusión del mapa a través de su publicación en abierto en la web de la revista El pequeño espectador.

\section{Resultados obtenidos}

En cuanto a los festivales, es preciso hacer notar que no existía previamente un catálogo ni un listado de festivales o ciclos teatrales destinados a esta franja de edad 0-3, por lo que el rastreo ha sido una tarea difícil, en la que resulta inevitable la incertidumbre de si habrá

Se puede consultar en la revista de crítica teatral El pequeño espectador: https:/elpequenoespectador.wordpress.com/mapa-de-teatro-para-bebes/ Agradecemos especialmente a Pere Pàmpols Farré, director artístico de la compañía Festuc Teatre, que puso en conocimiento de la Associació de Teatre per a Tots Els Públics nuestra iniciativa, y nos dio acceso a nuevas compañías del ámbito catalán que trabajan para la primerísima infancia; de igual modo, a Monti Cruz, de la compañía malagueña Petit Teatro, quien nos proporcionó el listado de todas las compañías de la región que trabajan para la infancia, facilitándonos el rastreo de aquellas que tienen propuestas específicas de 0 a 3 años. 
quedado sin reseñar algún acontecimiento teatral de pequeña o mediana importancia dentro de la geografía peninsular. Hecha esta salvedad, el inventario de festivales de teatro y artes escénicas para la primerísima infancia en el que hemos basado nuestro análisis de compañías incluye 23 eventos de reconocida relevancia, agrupables en dos categorías distintas, según se expresa en Tabla 1 y Tabla 2:

Tabla 1. Festivales y ciclos específicos para la franja 0-3 años.

\begin{tabular}{|c|c|c|}
\hline Nombre & Localidad / institución & Periodo $^{5}$ \\
\hline Festival Rompiendo el Cascarón & Madrid / Teatro Fernán Gómez & $\begin{array}{l}2005 \quad(\# 2013- \\
2015)-2019\end{array}$ \\
\hline Festival El Més Petit de Tots & Sabadell / Varias salas teatrales & $2005-2019$ \\
\hline Festival Despertamos a las Artes & Vigo-A Coruña / Fundación J. M. Barrie & $2008-2015$ \\
\hline Programa Acunándote & Granada / Diputación de Granada & $2009-2019$ \\
\hline Ciclo El Calderón en Pañales & Valladolid / Teatro Calderón & $2011-2019$ \\
\hline Ciclo El Principal con Chupete & $\begin{array}{l}\text { Palencia / Concejalía de Cultura de Palencia y } \\
\text { Teatro Principal }\end{array}$ & $2013-2019$ \\
\hline Festival das Núbebes & $\begin{array}{l}\text { Pontevedra / Ayuntamiento de Pontevedra y } \\
\text { Baobab Teatro }\end{array}$ & $2013-2019$ \\
\hline $\begin{array}{l}\text { Festival JEN Festival de Artes Es- } \\
\text { cénicas para Bebés }\end{array}$ & Zamora / Baychimo Teatro & 2014 \\
\hline Festival Txiki Txiki Txikia & Bizkaia & $2014-2016$ \\
\hline Festival Yo Soy Bebé & Granada / La Expositiva & $2014-2019$ \\
\hline $\begin{array}{l}\text { Festival TIF Teatro para la Infancia } \\
\text { y la Familia }\end{array}$ & Granada / Asociación EnCompañía & $2016-2019$ \\
\hline Festival Cucú & Zaragoza / Teatro Principal & $2016-2019$ \\
\hline Festival Chupetes & Madrid / Sala Tarambana & $2016-2019$ \\
\hline $\begin{array}{l}\text { Festival Meeting Baby (procede } \\
\text { del Baby Planet) }\end{array}$ & Santander / Escena Miriñaque & $2017-2019$ \\
\hline Ciclo Pequeños Actores & San Pedro de Alcántara, Málaga / Ayuntamiento & 2019 \\
\hline
\end{tabular}

Tabla 2. Festivales y ciclos genéricos de teatro infantil con inclusión de secciones para la franja 0-3 años.

\begin{tabular}{lll}
\hline \multicolumn{1}{c}{ Nombre } & \multicolumn{1}{c}{ Localidad / Institución } & \multicolumn{1}{c}{ Periodo $^{\mathbf{6}}$} \\
\hline $\begin{array}{l}\text { Semanas Internacionales de Teatro } \\
\text { para Niños }\end{array}$ & Madrid / Acción Educativa & $2005-2017$ \\
\hline Festival Teatralia & Madrid / Ayuntamiento de Madrid & $2000-2019$ \\
\hline Festival FETÉN & Gijón / Ayuntamiento de Gijón & $2005-2019$ \\
\hline Festival Te Veo & Zamora y Valladolid / Asociación Te Veo & $2005-2019$ \\
\hline Programa Abecedaria & Andalucía / Junta de Andalucía & $2013-2019$ \\
\hline Festival Teatrea & Logroño / Gobierno de La Rioja & $2013-2019$ \\
\hline Festival Barruguet & Santa Eularia des Riu, Ibiza / Ajuntament Santa & $2014-2019$ \\
& Eularia des Riu y Consell d'Eivissa & \\
\hline Festival Petit Teatre & San Joan d'Alacant & $2017-2019$ \\
\hline
\end{tabular}

En cuanto a las compañías dedicadas a la puesta en escena de espectáculos para la primerísima infancia, nuestra búsqueda arrojó un total de 91 compañías. El total de obras representadas para estas edades suma más de 150; este dato es seguramente aproximado, pues pue- den haberse representado, localmente y sin mucha difusión, espectáculos que hayan escapado a nuestra metodología de rastreo. El listado completo de las compañías registradas junto con los datos básicos de cada una se encuentra en el Anexo del presente artículo.

\footnotetext{
Nuestra investigación se cerró en 2019, por lo que los ciclos y festivales que marcan esa fecha de fin continúan (a menos que el futuro lo desmienta) activos.

6 Se consigna la fecha de inicio de programación recurrente para menores de 3 años, aunque algunos de estos festivales se iniciaron previamente con programación infantil en general.
} 


\section{Análisis}

\subsection{Ubicación geográfica}

Así pues, el mapa actual de teatro para la primerísima infancia recoge 91 compañías españolas que han dedicado, al menos, una obra de su repertorio para la franja de edad de 0-3 años. Una visión general de este mapa arroja luz sobre las comunidades autónomas y provincias donde esta práctica artística está más extendida ${ }^{7}$.

A la cabeza encontramos a la Comunidad de Madrid con 23 representantes: 18 en la capital y 5 más repartidas en Alcorcón, Aldea del Fresno, Fuenlabrada, Navalcarnero y Rivas.

La siguiente comunidad autónoma con más representación de compañías que trabajan el teatro para la primerísima infancia es Cataluña donde un total de 20 compañías han creado algún espectáculo: 19 son de la provincia de Barcelona (9 de la capital y 3 de Sabadell, además de compañías en otros municipios barceloneses como Cerdanyola, Igualada, Sant Cugat del Vallés, Sant Martí de Tous, dos en Santa Coloma de Gramanet, y Santa Maria de Palautordera) y una más en Corbins (Lleida).

En tercer lugar, encontramos Andalucía con 17 compañías: 5 en Sevilla (3 en la capital, otra en San Juan de Aznalfarache y una más en San José de la Rinconada), 3 en Málaga, 6 en Granada (4 en la capital, una en Alhedín y otra en Churriana de la Vega) y 3 en Jaén (en la capital, Alcalá la Real y Écija).

En cuarto lugar, estaría Galicia con 9 compañías representantes: 3 en A Coruña capital, otra en Abegondo y otra en Santiago de Compostela. Pontevendra estaría representada por una compañía en la capital y otras tres en O Grove, San Xoán y Vigo, respectivamente.

En quinto lugar, encontraríamos las compañías de Castilla y León con 6 compañías: en Burgos, Salamanca, Valladolid, Zamora, Sotillo del Rincón (Soria) y Turégano (Segovia).

En sexto lugar, la Comunidad Valenciana con 4 representantes: 3 en Castellón de la Plana (dos en la capital y una más en Benicarló) y una en Valencia capital.

A continuación, en este recorrido geográfico encontramos 3 compañías murcianas; 2 compañías en Asturias (Villaviciosa y Gijón); 2 en Cantabria (Santander); y 2 en Navarra (Pamplona).

Y finalmente, Aragón (Zaragoza), Castilla - La Mancha (Guadalajara), País Vasco (Vitoria) con 1 compañía cada una.

Si atendemos al total de las Comunidades Autónomas españolas, no se han encontrado datos de compañías dedicadas a la primerísima infancia en Extremadura, La Rioja, Islas Baleares, Islas Canarias, Ceuta y Melilla.

Esta distribución se refleja en la Figura 1. Como se aprecia, era previsible que Madrid y Barcelona aglutinaran el mayor número de compañías, dada su importancia demográfica y cultural. Por los mismos motivos, también resulta lógica la presencia de muchas compañías en Andalucía (la región con más habitantes del país), y en el resto de Comunidades Autónomas la representación está en consonancia con su peso demográfico, con excepciones que no parecen muy significativas.

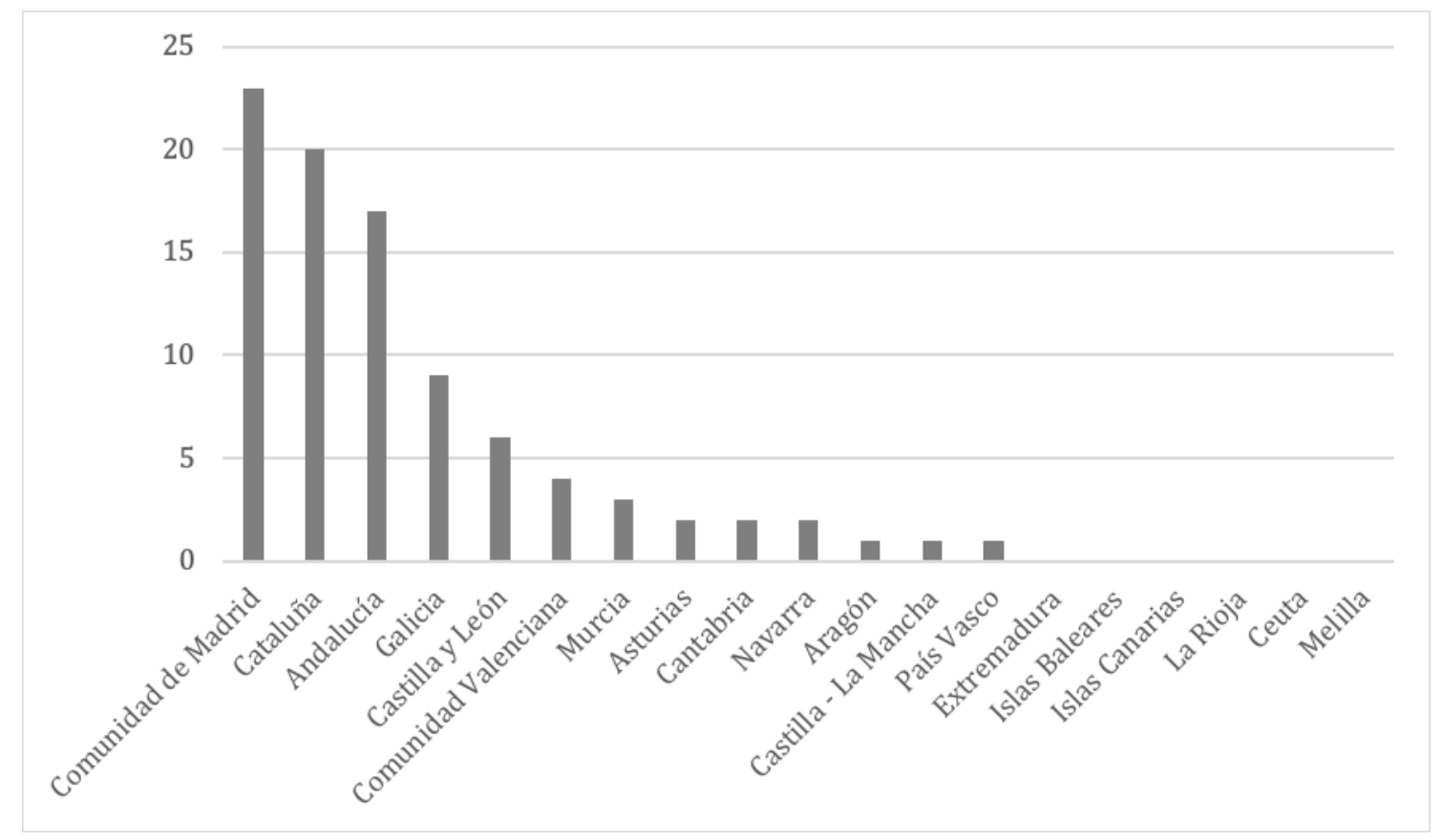

Figura 1. Distribución por comunidades de las compañías para la primerísima infancia

\footnotetext{
Los datos de ubicación de las compañías se han extraído de sus páginas web, aunque no siempre se muestran en ellas de modo preciso, entendemos que por voluntad de los propios profesionales. En los contactos que se realizaron con las compañías por correo electrónico algunas puntualizaron de una manera más exacta (indicando municipio o, incluso, dirección concreta) su ubicación. Por ello, a pesar de que en el mapa pudieran existir ligeras imprecisiones de ubicación, la distribución por municipios y provincias está ajustada.
} 


\subsection{Clasificación en categorías genéricas orientativas}

En relación con la tipología de arte escénica que desempeñan de manera prioritaria ${ }^{8}$ las compañías fijadas en el mapa, un recuento numérico arroja las siguientes cifras:

- Teatro, teatro-instalación y/o teatro sensorial: 45 compañías. Incluimos en esta categoría las obras cuyo fundamento estético se encuentra en el teatro de actores, en las que ellos representan un argumento, o guían a los espectadores/jugadores por un itinerario de exploración sensorial. Los límites del teatro de actores y de la instalación artística son a veces difusos en las obras más experimentales de este género.

- Teatro de títeres, de objetos y/o de sombras: 18 compañías. Incluimos en esta categoría las obras en las que hay un papel preponderante de marionetas, títeres $\mathrm{u}$ otros procedimientos materiales que derivan la representación física de los personajes y eventos a los objetos manipulados por los actores. El término "teatro de objetos" parece ofrecer connotaciones más actuales que el de "títeres" [Pavis 2008: 449], sin embargo, muchas de estas compañías se denominan "de títeres" en sus propias páginas web.

- Danza teatro: 14 compañías, una de las cuales hace específicamente flamenco. Se incluyen aquí las obras en las que la danza y la coreografía son el vehículo principal de construcción argumental y escénica, en un modelo que hunde sus raíces en Pina Bausch.

- Teatro música: 7 compañías. En esta categoría incluimos los espectáculos centrados en la interpretación musical, incluyendo conciertos para bebés.

- Teatro circo: reunimos en esta categoría a 7 compañías, de las cuales 2 se dedican a acrobacia, 4 a clown, y 1 a magia. Se trata de creaciones escénicas centradas en géneros tradicionalmente circenses.

Hemos excluido de nuestro análisis los talleres que en ocasiones se han producido en festivales y ciclos, como talleres de movimiento y expresión corporal, o talleres de percusión, por ejemplo. Recogemos la proporción de obras de cada tipo en la Figura 2.

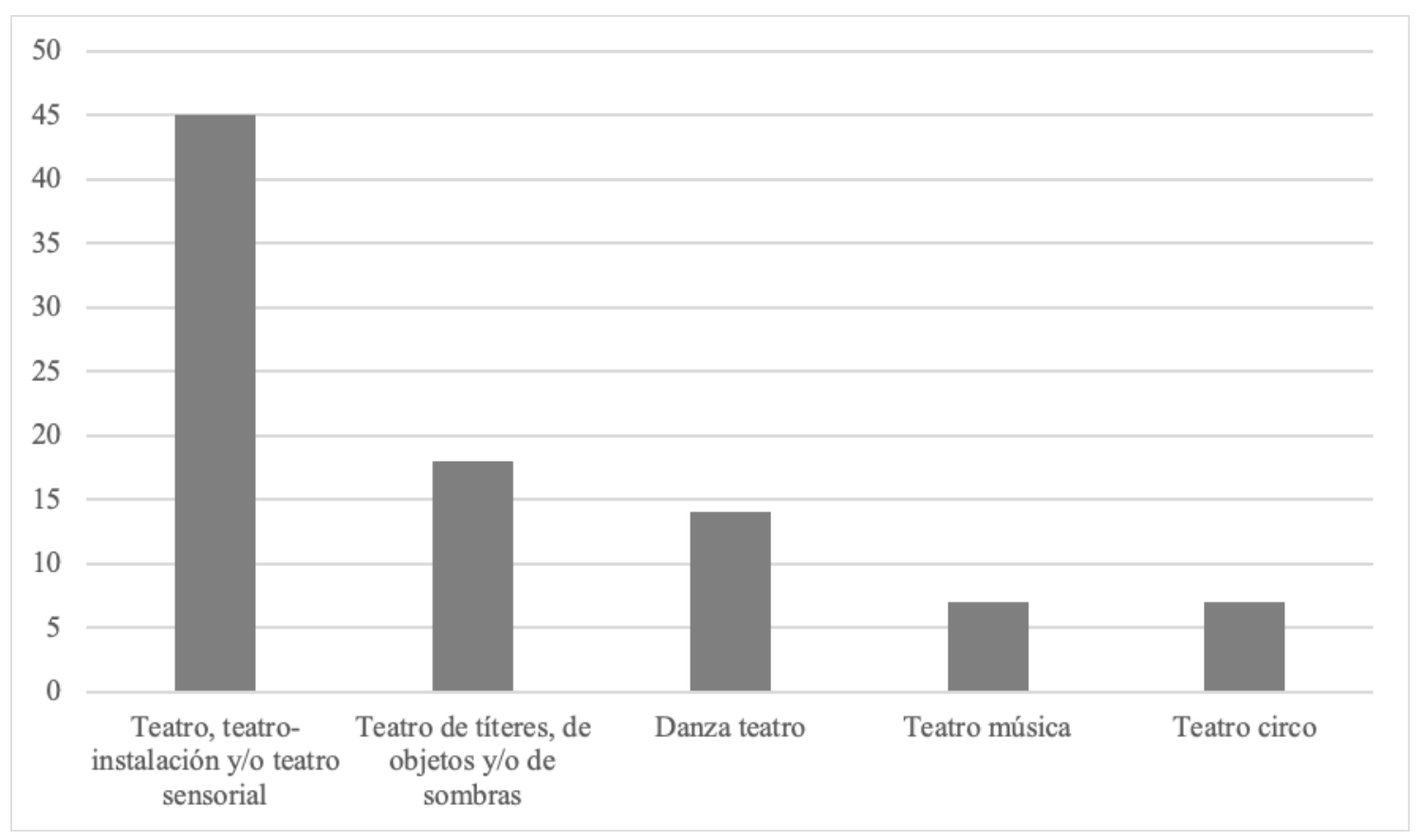

Figura 2. Tipos de espectáculos escénicos para la primerísima infancia

\subsection{Evolución cronológica de representaciones}

Otro dato interesante surge del análisis de los años de estreno de las obras más veteranas de las compañías que aparecen en el mapa. Ha sido, tal vez, el dato más complejo de extraer, puesto que en las páginas web de las compañías apenas aparece y se tuvo que recabar gracias al contacto directo con las propias compañías, y rastreando en notas de prensa de periódicos digitales y webs. Por ello, a día de hoy no damos por segura la fecha de estreno de la primera obra para 0-3 años de 39 de las 91 compañías recopiladas en el mapa. No obstante, los datos son suficientes para poder apreciar un desarrollo exponencial en las artes escénicas destinadas a la primerísima infancia, especialmente notable entre 2016 y 2019. Se exponen los años en que una nueva compañía se estrenó en la franja 0-3 en la Figura 3. 


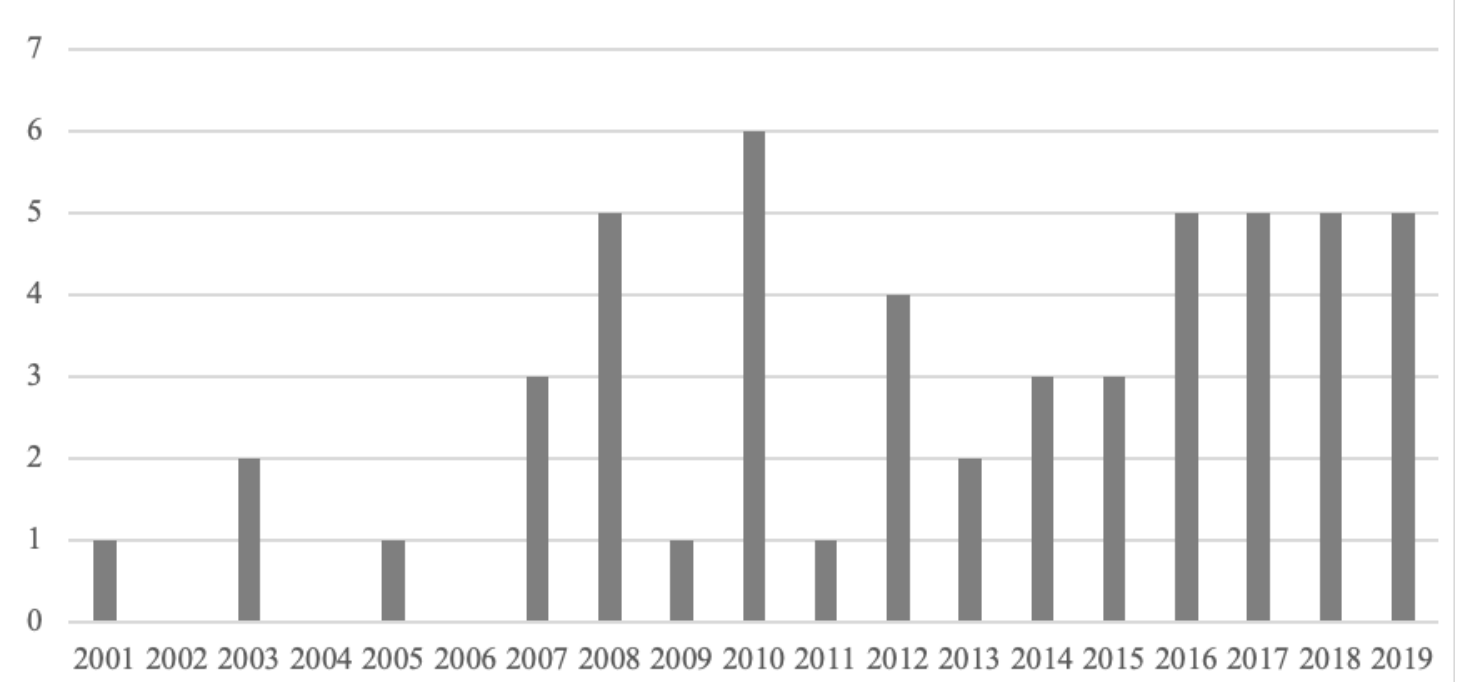

Figura 3. Inicio de las compañías en el teatro para 0-3 años. Cada número del eje Y indica una compañía nueva que inicia su actividad ese año

\subsection{Principales compañías}

Contabilizadas las compañías y sus obras, descubrimos que muchas de ellas solo han puesto en escena hasta la fecha uno o dos espectáculos para la primerísima infan- cia. De hecho, son muy pocas las que poseen más de cuatro obras para estas edades, lo cual nos permite ofrecer esta Tabla 3 enumerando las que han desarrollado una actividad creadora mayor de 3 obras:

Tabla 3. Compañías con mayor producción para la franja 0-3 años

\begin{tabular}{lllll}
\hline \multicolumn{1}{c}{ Compañía } & \multicolumn{1}{c}{ Localidad } & $\begin{array}{c}\text { Número } \\
\text { de obras }\end{array}$ & Tipo de obras & $\begin{array}{c}\text { Año de inicio } \\
\text { (si se conoce) }\end{array}$ \\
\hline La Casa Incierta & Madrid ${ }^{9}$ & 13 & Teatro & 2003 \\
\hline Tyl Tyl & Madrid -Navalcarnero & 10 & Teatro & 2010 \\
\hline Teloncillo Teatro & Valladolid & 7 & Teatro & 2010 \\
\hline Da.Te Danza & Granada & 7 & Danza teatro & 2003 \\
\hline Nas Teatro & Madrid - Rivas & 7 & Teatro & 2013 \\
\hline Teatro Paraíso & Vitoria-Gasteiz & 6 & Teatro & 2005 \\
\hline Baobab Teatro & Pontevedra & 6 & Teatro & 2014 \\
\hline Cia Patawa & Barcelona - San Cugat del Vallés & 6 & Títeres & 2014 \\
\hline Imaginart & Barcelona - Sabadell & 5 & Teatro & - \\
\hline La Petita Malugaluga & Barcelona - Sabadell & 5 & Teatro música & - \\
\hline Eugenia Manzanera & Madrid - Aldea del Fresno & 5 & Teatro & 2010 \\
\hline Teatro La Paca & Jaén & 5 & Teatro & - \\
\hline Ultramarinos de Lucas & Guadalajara & 4 & Teatro & 2001 \\
\hline Caramuxo Teatro & A Coruña & 4 & Teatro & - \\
\hline Compañía La Clá & Madrid & 4 & Danza teatro & 2008 \\
\hline Zumo Animaciones & Madrid & 4 & Teatro & 2017 \\
\hline
\end{tabular}

Es posible ofrecer también un listado de las compañías por orden de antigüedad del primer montaje. Considerando la salvedad, ya comentada, de que para algunas de las compañías (aunque suelen ser las más recientes) no hemos podido aclarar las fechas de estreno, ofrecemos un listado de las anteriores a 2010 en la Tabla 4: 
Tabla 4. Compañías veteranas en el teatro para la primerísima infancia

\begin{tabular}{|c|c|c|c|}
\hline Compañía & Localidad & $\begin{array}{c}\text { Tipo de } \\
\text { obras }\end{array}$ & $\begin{array}{c}\text { Año de } \\
\text { inicio }\end{array}$ \\
\hline Ultramarinos de Lucas & Guadalajara & Teatro & 2001 \\
\hline Da.Te Danza & Granada & Danza teatro & 2003 \\
\hline La Casa Incierta & Madrid & Teatro & 2003 \\
\hline Teatro Paraíso & Vitoria-Gasteiz & Teatro & 2005 \\
\hline Aracaladanza & Madrid & Danza teatro & 2007 \\
\hline Compañía Ñía & Sevilla & Teatro & 2007 \\
\hline La Compañía Barataria & $\begin{array}{l}\text { Sevilla - San Juan de Aznalfara- } \\
\text { che }\end{array}$ & Teatro & 2007 \\
\hline Arena en los Bolsillos & Granada & Títeres & 2008 \\
\hline Compañía La Clá & Madrid & Danza teatro & 2008 \\
\hline LaSal Teatro & Granada & Teatro & 2008 \\
\hline Susi Lillo & Madrid & Títeres & 2008 \\
\hline Tian Gombau-L'Home Dibuixat & Castellón de la Plana & Títeres & 2008 \\
\hline Fes t'ho com Vulguis & Barcelona -Hospitalet & Teatro & 2009 \\
\hline Eugenia Manzanera & Madrid - Aldea del Fresno & Teatro & 2010 \\
\hline Maluka-PeKa & Sevilla - San José de la Rinconada & Teatro & 2010 \\
\hline Mons Dansa i Educació (antes Nats Nus Dansa) & Barcelona & Danza teatro & 2010 \\
\hline Teloncillo Teatro & Valladolid & Teatro & 2010 \\
\hline Tyl Tyl & Madrid -Navalcarnero & Teatro & 2010 \\
\hline Zig Zag Danza & Gijón & Danza teatro & 2010 \\
\hline
\end{tabular}

A continuación, si se cruzan ambas tablas, se deriva un listado de compañías que reúnen dos requisitos: tener un número significativo de obras para la primerísima infancia y poseer un recorrido amplio en la historia del género en España. De este cotejo, pues, el resultado es el siguiente:

\section{Compañía La Clá \\ Da.Te Danza \\ Eugenia Manzanera \\ La Casa Incierta \\ Teatro Paraíso \\ Teloncillo Teatro \\ Tyl Tyl \\ Ultramarinos de Lucas}

Tal vez en este breve listado de ocho compañías no estén todas las que han marcado un hito en la historia del género $^{10}$; pero sí todas las que están lo han hecho. Podemos decir que, tanto por la actividad creadora como por la cronología temprana de las obras, estas compañías representan algo así como el canon incipiente, un primer referente estético y artístico del teatro para la primerísima infancia en España. Su presencia en los principales festivales es constante, sus obras son programadas en ciclos específicos, y han ganado premios como el FETÉN, el Max o el Nacional de Artes Escénicas para la Infancia.
Lo que además podemos constatar en esta aproximación a las compañías y a las obras es que no solamente existe una diferencia de estilos y formas escénicas entre todas estas compañías, sino también distintos grados de experimentación, exploración de lenguajes y calidad del tratamiento artístico. En esta investigación hemos tratado de apartar de nosotros el enfoque crítico y valorativo, y nos hemos limitado a consignar asépticamente las compañías y obras existentes en el ecosistema del teatro para la primerísima infancia, con el fin de reflejarlas en el mapa. Pero deseamos manifestar la constatación de que, de todo el listado analizado, no todas las compañías se encuentran al mismo nivel en cuanto al trabajo artístico. Una vez más, dicho análisis formará parte de investigaciones posteriores.

\section{Conclusiones}

El Mapa de las compañías y espectáculos para la primerísima infancia en España, disponible en abierto para los especialistas, es una herramienta de gran utilidad para un campo de investigación que se ha abierto en la escena teatral en los últimos años. El el presente artículo nos ha permitido hacer un análisis de la implantación geográfica de estos espectáculos, y hemos podido evidenciar el florecimiento de este nuevo género en un ecosistema propio. 
La distribución de compañías por regiones de España está en relación con su peso demográfico y relevancia de mercado cultural. Los grandes núcleos urbanos y sus áreas metropolitanas y extrarradio se llevan la palma en cuanto a producción teatral. Solo llama la atención, como se ha señalado, que no haya compañías de teatro para 0-3 años en algunas regiones que en cambio sí ofrecen alguna programación regular (como La Rioja, o Islas Baleares). Esto nos permite concluir que, si bien es habitual que los festivales sucedan en torno a compañías o cúmulos de compañías con cierta trayectoria en estos espectáculos, no es una ley determinante.

Otra constatación importante que se deriva del análisis de las compañías y del tipo de espectáculos que ofrecen, es que algunos subgéneros tienen un peso muy relevante. El teatro de títeres, es sabido, ha incluido desde siempre edades infantiles, por lo que no es tan raro que se extienda "hacia abajo". Llama más la atención la presencia de compañías y obras de danza teatro, que encuentran en el público de 0 a 3 años un destinatario al parecer muy propicio a atender a su lenguaje; de algún modo, y como se ha señalado en otra parte [Llergo Ojalvo y Ceballos Viro 2019: 89-96], otros lenguajes tienen cabida frente a un auditorio que no domina aún el lenguaje verbal.

Finalmente, y como conclusión más evidente, la descripción y el análisis ofrecidos aquí dan pruebas del nacimiento y la corta vida del teatro para la primerísima infancia en España. Llegó a nosotros con el siglo XXI. Pero desde entonces, como los bebés, ha ido creciendo y ganando peso constantemente, con cada vez más compañías, festivales y obras en escena. La evidencia gráfica aquí presentada demuestra su buen estado de salud y permite augurar un desarrollo creciente en los años futuros.

\section{Referencias bibliográficas}

Álvarez Uria, Amaia, Alaitz Tresserras Angulo, Edu Zelaieta Anta y María Teresa Vizacarra Morales (2015): “Juego, teatro y educación infantil. La obra teatral Kubik y su valor pedagógico-artístico", Enseñanza \& Teaching: Revista Interuniversitaria de Didáctica, 33, 1: 143-161. DOI: 10.14201/et2015331143161, Fecha de consulta: 05-V-2020.

Ben Soussan, Patrick, y Pascale Mignon (2006): Les bébés vont au théâtre, Toulouse, Erès.

Camino Ortiz, Igor, Edu Zelaieta Anta, Amaia Álvarez Uria, y Alaitz Treserras Angulo (2015): “Un reto innovador en la formación del profesorado de Educación Infantil: la obra teatral Kubik”, Profesorado: Revista de Currículum y Formación del Profesorado, 19, 2: 429-440.

Fletcher-Watson, Ben, Sue Fletcher-Watson, Jeanne McNaughton and Anna Birch (2014): "From Cradle to Stage: How Early Years Performing Arts Experiences Are Tailored to the Developmental Capabilities of Babies and Toddlers", Youth Theatre Journal, 28, 2: 130-146. DOI: 10.1080/08929092.2014.940075, Fecha de consulta: 05-V-2020.

Frabetti, Roberto, Marina Manferrari, Franca Marchesi, y Paola Vassuri (2000): Il nido e il teatro, Bologna, Pendragon - La Baracca.

Hovik, Lise. (2014): The Red Shoes Project: Theatre for the Very Young As Artistic Research, Article 5 in PhD. Thesis (in English), Recurso web <http://teaterfot.no/wp-content/uploads/2012/04/Artikkel-5.The-Red-Shoes-Project-Hovik-3.12revidert-1.pdf $>$, Fecha de consulta: 05-V-2020.

- (2018): "The Red Shoes Project Revisited", Journal for Artistic Research, 16, Recurso web <https://www.researchcatalogue. net/view/56059/56060> Fecha de consulta: 05-V-2020.

Llergo Ojalvo, Eva, e Ignacio Ceballos Viro (2019): "El teatro para la primerísima infancia en España”, AILIJ: Anuario de Investigación en Literatura Infantil y Juvenil, 17: 83-100. DOI: 10.35869/ailij.v0i17.1426, Fecha de consulta: 05-V-2020.

Pavis, Patrice (2008): Diccionario teatral, Barcelona, Paidós.

Ribagorda, Miguel (2018): El espectador-intérprete: aproximación neurocientífica a la comunicación y la recepción teatral, Tesis, Universidad Complutense de Madrid.

Schneider, Wolfgang (2009): Theatre for Early Years. Research in Performing Arts for Children from Birth to Three, Frankfurt, Peter Lang.

\section{Anexo: Listado de compañías con obras para la primerísima infancia}

\begin{tabular}{lllll}
$\begin{array}{l}\text { Comunidad Autó- } \\
\text { noma }\end{array}$ & Provincia & Compañía & Tipo de obras & $\begin{array}{l}\text { Año de inicio en } \\
\text { la franja 0-3 años } \\
\text { (si se conoce) }\end{array}$ \\
\hline Andalucía & Granada & Toto Fabris & Teatro música & 2008 \\
\hline Andalucía & Granada & LaSal Teatro & Teatro & $\begin{array}{l}\text { Títeres, objetos y/o } \\
\text { sombras }\end{array}$ \\
\hline Andalucía & Granada & Afinal & Danza teatro & 2003 \\
\hline Andalucía & Granada & Da.Te Danza & $\begin{array}{l}\text { Títeres, objetos y/o } \\
\text { sombras }\end{array}$ & 2008 \\
\hline Andalucía & Granada & Arena en los Bolsi- & &
\end{tabular}




\begin{tabular}{|c|c|c|c|c|}
\hline Andalucía & Granada-Alhendín & $\begin{array}{l}\text { Compañía El Señor } \\
\text { Sapo }\end{array}$ & Teatro & 2019 \\
\hline Andalucía & Jaén & Teatro La Paca & Teatro & \\
\hline Andalucía & Jaén-Alcalá la Real & La Canela & $\begin{array}{l}\text { Títeres, objetos y/o } \\
\text { sombras }\end{array}$ & \\
\hline Andalucía & Jaén-Écija & A la Sombrita & $\begin{array}{l}\text { Títeres, objetos y/o } \\
\text { sombras }\end{array}$ & 2011 \\
\hline Andalucía & Málaga & Índigo Teatro & Teatro & \\
\hline Andalucía & Málaga & Petit Teatro & $\begin{array}{l}\text { Títeres, objetos y/o } \\
\text { sombras }\end{array}$ & 2015 \\
\hline Andalucía & Málaga & $\begin{array}{l}\text { Compañía Isabel } \\
\text { Alba }\end{array}$ & Teatro & 2019 \\
\hline Andalucía & Sevilla & Anabel Veloso & $\begin{array}{l}\text { Danza teatro / } \\
\text { Flamenco }\end{array}$ & \\
\hline Andalucía & Sevilla & Proyecto Nana & Danza teatro & 2018 \\
\hline Andalucía & Sevilla & Compañía Ñía & Teatro & 2007 \\
\hline Andalucía & $\begin{array}{l}\text { Sevilla - San José de la } \\
\text { Rinconada }\end{array}$ & Maluka-PeKa & Teatro & 2010 \\
\hline Andalucía & $\begin{array}{l}\text { Sevilla - San Juan de } \\
\text { Aznalfarache }\end{array}$ & $\begin{array}{l}\text { La Compañía Bara- } \\
\text { taria }\end{array}$ & Teatro & 2007 \\
\hline Aragón & Zaragoza & $\begin{array}{l}\text { Promotora de Acción } \\
\text { Infantil (PAI) }\end{array}$ & Teatro & \\
\hline Asturias & Villaviciosa & Mar Rojo Teatro & Teatro & 2017 \\
\hline Asturias & Gijón & Zig Zag Danza & Danza teatro & 2010 \\
\hline Cantabria & Santander & Escena Miriñaque & Teatro & \\
\hline Cantabria & Santander & Quasar Teatro & Teatro & \\
\hline Castilla La Mancha & Guadalajara & $\begin{array}{l}\text { Ultramarinos de } \\
\text { Lucas }\end{array}$ & Teatro & 2001 \\
\hline Castilla y León & Burgos & Margarito y Cía & Teatro & \\
\hline Castilla y León & Salamanca & Katua y Galea & Teatro & 2012 \\
\hline Castilla y León & Segovia - Turégano & $\begin{array}{l}\text { Títeres de María Pa- } \\
\text { rrato }\end{array}$ & $\begin{array}{l}\text { Títeres, objetos y/o } \\
\text { sombras }\end{array}$ & \\
\hline Castilla y León & $\begin{array}{l}\text { Soria - Sotillo del } \\
\text { Rincón }\end{array}$ & Teatro de la Luna & $\begin{array}{l}\text { Títeres, objetos y/o } \\
\text { sombras }\end{array}$ & \\
\hline Castilla y León & Valladolid & Teloncillo Teatro & Teatro & 2010 \\
\hline Castilla y León & Zamora & Baychimo Teatro & $\begin{array}{l}\text { Títeres, objetos y/o } \\
\text { sombras }\end{array}$ & \\
\hline Cataluña & Barcelona & Aboon Teatre & Teatro & \\
\hline Cataluña & Barcelona & Animal Religion & Circo & 2019 \\
\hline Cataluña & Barcelona & Big Bouncers & Danza teatro & 2018 \\
\hline Cataluña & Barcelona & Blink Flash & Danza teatro & 2017 \\
\hline Cataluña & Barcelona & $\begin{array}{l}\text { Compañía Roberto } \\
\text { G. Alonso }\end{array}$ & Danza teatro & 2012 \\
\hline Cataluña & Barcelona & David Ymbernon & Teatro & 2019 \\
\hline Cataluña & Barcelona & $\begin{array}{l}\text { Mons Dansa i Educa- } \\
\text { ció (antes Nats Nus } \\
\text { Dansa) }\end{array}$ & Danza teatro & 2010 \\
\hline Cataluña & Barcelona & Roseland Musical & Danza teatro & 2016 \\
\hline Cataluña & Barcelona - Cerdanyola & Pessic de Circ & Circo & \\
\hline Cataluña & Barcelona -Hospitalet & Fes t'ho com Vulguis & Teatro & 2009 \\
\hline Cataluña & Barcelona - Igualada & Farrés Brothers y Cía & $\begin{array}{l}\text { Títeres, objetos y/o } \\
\text { sombras / Sombras }\end{array}$ & 2019 \\
\hline Cataluña & Barcelona - Sabadell & La Bleda & Circo / Clown & \\
\hline
\end{tabular}




\begin{tabular}{|c|c|c|c|c|}
\hline Cataluña & Barcelona - Sabadell & $\begin{array}{l}\text { La Petita Malumalu- } \\
\text { ga }\end{array}$ & Teatro música & 2011 \\
\hline Cataluña & Barcelona - Sabadell & Imaginart & Teatro & \\
\hline Cataluña & $\begin{array}{l}\text { Barcelona - San Cugat } \\
\text { del Vallés }\end{array}$ & Cia Patawa & $\begin{array}{l}\text { Títeres, objetos y/o } \\
\text { sombras }\end{array}$ & 2014 \\
\hline Cataluña & $\begin{array}{l}\text { Barcelona - San Martin } \\
\text { de Tous }\end{array}$ & Teatre $\mathrm{Nu}$ & $\begin{array}{l}\text { Títeres, objetos y/o } \\
\text { sombras }\end{array}$ & \\
\hline Cataluña & $\begin{array}{l}\text { Barcelona - Santa Colo- } \\
\text { ma de Gramanet }\end{array}$ & Tot Terreny & Circo / Clown & 2016 \\
\hline Cataluña & $\begin{array}{l}\text { Barcelona - Santa Colo- } \\
\text { ma de Gramanet }\end{array}$ & Ponten Pie & Teatro & \\
\hline Cataluña & $\begin{array}{l}\text { Barcelona - Santa Maria } \\
\text { de Palautordera }\end{array}$ & Txo Titelles & $\begin{array}{l}\text { Títeres, objetos y/o } \\
\text { sombras }\end{array}$ & \\
\hline Cataluña & Lleida - Corbíns & Festuc Teatre & $\begin{array}{l}\text { Títeres, objetos y/o } \\
\text { sombras }\end{array}$ & \\
\hline Madrid & Madrid & Aracaladanza & Danza teatro & 2007 \\
\hline Madrid & Madrid & Demolécula & Danza teatro & \\
\hline Madrid & Madrid & Nido Dadá & Teatro & \\
\hline Madrid & Madrid & CamelCat & $\begin{array}{l}\text { Títeres, objetos y/o } \\
\text { sombras }\end{array}$ & \\
\hline Madrid & Madrid & Baraka Teatro & Teatro & \\
\hline Madrid & Madrid & La Casa Incierta & Teatro & 2003 \\
\hline Madrid & Madrid & Compañía La Clá & Danza teatro & 2008 \\
\hline Madrid & Madrid & El Efecto Galatea & Teatro & 2014 \\
\hline Madrid & Madrid & Kazumbo Teatro & Circo / Clown & 2018 \\
\hline Madrid & Madrid & María Escobar & Danza teatro & 2015 \\
\hline Madrid & Madrid & Martelache & Teatro & 2012 \\
\hline Madrid & Madrid & Angosta Di Mente & Circo / Clown & 2016 \\
\hline Madrid & Madrid & Factoría Urogallo & Teatro & 2016 \\
\hline Madrid & Madrid & Marissa Palique & Teatro & 2016 \\
\hline Madrid & Madrid & Susi Lillo & $\begin{array}{l}\text { Títeres, objetos y/o } \\
\text { sombras }\end{array}$ & 2008 \\
\hline Madrid & Madrid & Zapatos de Papel & Teatro & 2017 \\
\hline Madrid & Madrid & Zumo Animaciones & Teatro & 2017 \\
\hline Madrid & Madrid & Xsiacaso & Danza teatro & 2012 \\
\hline Madrid & Madrid -Alcorcón & Okina Teatro & Teatro & \\
\hline Madrid & $\begin{array}{l}\text { Madrid - Aldea del } \\
\text { Fresno }\end{array}$ & Eugenia Manzanera & Teatro & 2010 \\
\hline Madrid & Madrid -Fuenlabrada & Tulumba Teatro & Teatro & 2017 \\
\hline Madrid & Madrid -Navalcarnero & Tyl Tyl & Teatro & 2010 \\
\hline Madrid & Madrid - Rivas & Ñas Teatro & Teatro & 2013 \\
\hline $\begin{array}{l}\text { Comunidad Valen- } \\
\text { ciana }\end{array}$ & Castellón de la Plana & $\begin{array}{l}\text { Tian Gombau-L'Ho- } \\
\text { me Dibuixat }\end{array}$ & $\begin{array}{l}\text { Títeres, objetos y/o } \\
\text { sombras }\end{array}$ & 2008 \\
\hline $\begin{array}{l}\text { Comunidad Valen- } \\
\text { ciana }\end{array}$ & Castellón de la Plana & Xarop Teatre & $\begin{array}{l}\text { Títeres, objetos y/o } \\
\text { sombras }\end{array}$ & 2018 \\
\hline $\begin{array}{l}\text { Comunidad Valen- } \\
\text { ciana }\end{array}$ & $\begin{array}{l}\text { Castellón de la Plana - } \\
\text { Benicarló }\end{array}$ & Factoría Los Sánchez & Teatro música & 2013 \\
\hline $\begin{array}{l}\text { Comunidad Valen- } \\
\text { ciana }\end{array}$ & Valencia & Panicmap & Teatro & \\
\hline País Vasco & Vitoria-Gasteiz & Teatro Paraíso & Teatro & 2005 \\
\hline Galicia & A Coruña & Teatro Da Semente & Teatro & \\
\hline Galicia & A Coruña & Caramuxo Teatro & Teatro & \\
\hline
\end{tabular}




\begin{tabular}{lllll}
\hline Galicia & A Coruña & $\begin{array}{l}\text { Katarsis Educación y } \\
\text { Teatro }\end{array}$ & Teatro \\
\hline Galicia & A Coruña - Abegondo & Trompicallo & $\begin{array}{l}\text { Títeres, objetos y/o } \\
\text { sombras }\end{array}$ & \\
\hline Galicia & $\begin{array}{l}\text { A Coruña - Santiago de } \\
\text { Compostela }\end{array}$ & Títeres Babaluva & $\begin{array}{l}\text { Títeres, objetos y/o } \\
\text { sombras }\end{array}$ & \\
\hline Galicia & Pontevedra & Baobab Teatro & Teatro & 2014 \\
\hline Galicia & Pontevedra - O Grove & Xarope Tulú & Teatro & 2015 \\
\hline Galicia & Pontevedra - San Xoán & $\begin{array}{l}\text { Cé Orquestra } \\
\text { Pantasma }\end{array}$ & Teatro música & \\
\hline Galicia & Pontevedra -Vigo & El Baúl de la Tía Tola & Teatro & \\
\hline Murcia & Murcia & Fictoria & Teatro música & \\
\hline Murcia & Murcia & Fábula Teatro & Teatro música & \\
\hline Murcia & Murcia & Silfo Teatro & Teatro & \\
\hline Navarra & Pamplona & Pasadas las 4 & Teatro música & \\
\hline Navarra & Pamplona & Navarcadabra & Circo / Magia & 2018 \\
\hline
\end{tabular}

